\title{
Layer by layer synthesis of zinc-iron layered hydroxy sulfate for electrocatalytic hydrogen evolution from ethanol in alkali media
}

\author{
D. S. Dmitriev, V. I. Popkov \\ Ioffe Institute, 194021 Saint Petersburg, 26 Polytechnicheskaya street, Russia \\ vadim.i.popkov@gmail.com
}

DOI 10.17586/2220-8054-2019-10-4-480-487

\begin{abstract}
This paper proposes a method for producing nanocomposite electrocatalytic coatings based on zinc-iron layered hydroxy sulfate $\mathrm{Zn}_{2} \mathrm{Fe}_{4}(\mathrm{OH})_{12} \mathrm{SO}_{4}$. $8 \mathrm{H}_{2} \mathrm{O}$ and iron(III) hydroxide $\mathrm{Fe}(\mathrm{OH})_{3}$ using the successive ionic layer deposition (SILD) method. The obtained materials were investigated with the methods of SEM and EDX, XRD, FTIR spectroscopy, and also were analyzed their electrocatalytic performance. These compounds are formed on the surface of the substrate in nanosheets shape with an average size of 6-17 nm, which self-organized into coral-like agglomerates. It was shown that by varying the anionic component of the reaction solution $-\mathrm{NO}^{3-}, \mathrm{SO}_{4}^{2-}$ or $\mathrm{Cl}^{-}$, effective control of the $2 \mathrm{D}$ nanocrystals phase composition is possible. It has been determined that electrocatalytic materials based on $\mathrm{Zn}_{2} \mathrm{Fe}_{4}(\mathrm{OH})_{12} \mathrm{SO}_{4} \cdot 8 \mathrm{H}_{2} \mathrm{O}$ and $\mathrm{Fe}(\mathrm{OH})_{3}$ are active in the process of hydrogen evolution from alkaline water-alcohol solutions. In result overpotential value of hydrogen evolution reaction at $10 \mathrm{~mA} \mathrm{~cm}{ }^{-2}$ decreases about $\sim 10 \%$, as well as energy consumption to carry out this process reduces about $8-12 \%$. as shown from the decline of the Tafel slope. The developed materials have high cyclic stability and short non-stationary mode, which allows them to be considered as the base of electrocatalysts for the processes of hydrogen evolution from ethanol in an alkaline medium.
\end{abstract}

Keywords: successive ionic layer deposition, layered hydroxide, electroreforming, hydrogen evolution reaction, electrocatalytic, ethanol reforming.

Received: 13 June 2019

Revised: 18 August 2019

\section{Introduction}

The reaction of hydrogen evolution (HER) from aqueous and aqueous-alcoholic solutions under the electric current is one of the main processes of modern electrochemical production. This process is especially interesting for the developing fuel cell technology, in which hydrogen is the main source of energy [1-6], as well as for the increasingly popular electroreforming process, where hydrogen is released during electrolysis of aqueous and organic electrolytes at direct current [7-10]. One of the electroreforming applications is the utilization of biomass processing products in water-alcohol solution form, mainly based on methyl and ethyl alcohols (from 2 to 6 mol $\mathrm{L}^{-1}$ ). For the practical implementation of the electroreforming of such products, it is necessary to increase the electrical conductivity of these solutions, which is usually produced by adding potassium or sodium hydroxides [11-13].

For electroreforming, electrodes from noble metals $(\mathrm{Pt}, \mathrm{Pd})$ and iron group metals $(\mathrm{Fe}, \mathrm{Ni}, \mathrm{Co})$ can be used. The main requirements for electrode materials are high efficiency and low cost, determined, among other parameters, by a slight overpotential of HER. For noble metals, the overpotential value is low (up to 40-60 $\mathrm{mV}$ at a current density of $10 \mathrm{~mA} \mathrm{~cm}^{-2}$ ), but their high cost restricts their active use as electrodes. Iron group metals are relatively cheaper than noble metals, but their overpotential value is $300-500 \mathrm{mV}$ at a current density of $10 \mathrm{~mA} \mathrm{~cm}^{-2}$ [14-18]. Also, compounds of various classes, called electrocatalysts, are used as electrode materials: oxides (hydroxides), sulfides, phosphides, nitrides, and etc. [19-22]. The advantage of electrocatalysts over pure metals or alloys is their high efficiency at a relatively low cost. Under the effectiveness of electrocatalysts, in addition to low overpotential, they also imply high stability of the material during electrolysis, short non-stationary mode and efficient conversion of electrical energy, determined by the Tafel slope according to its physical meaning [23]. The most common electrocatalytic materials are compounds of molybdenum, tungsten, nickel and cobalt. Some of them, for example, $\mathrm{MoS}_{2}$ attains an overpotential value of 50-80 mV [24-30]. Therefore, the synthesis of compounds exhibiting electrocatalytic activity in HER at electrochemical reforming as electrode materials is currently an important scientific and practical task.

The work of the electrocatalyst is influenced by the nature of its components as well as the morphology and structure, mainly determined by the conditions and the synthetic route. One of the most promising methods for producing thin film electrocatalysts on the metal surface is the successive ionic layer deposition (SILD) approach, which is one of layer by layer synthesis methods [31]. This method is based on the sequential adsorption of cations and anions, forming a poorly soluble compound from a solution on the surface of a substrate. Automation of parameters allows to adjust the thickness of the electrocatalyst films, the selection of the composition and morphology. This method can be easily scalable for the synthesis of electrocatalytic materials at a standard temperature with simple hardware and the use of low-cost reagents [32-38]. 
In this paper, a new technique is proposed for producing nanocomposite based on zinc-iron layered hydroxy sulfate (ZF-LHS) as electroreforming materials in an alcohol solution with the aim of hydrogen evolution. The synthesis is carried out in solutions of the Mohr's salt $\left(\left(\mathrm{NH}_{4}\right)_{2} \mathrm{Fe}\left(\mathrm{SO}_{4}\right)_{2}\right)$ and ammonium zinc complexes using $\mathrm{Zn}\left(\mathrm{NO}_{3}\right)_{2}$, $\mathrm{ZnSO}_{4}$ and $\mathrm{ZnCl}_{2}$ as a precursor. By varying the ion-contain of the reaction, solutions and additional heat treatment, electrocatalysts with different composition, structure, and morphology are obtained in the form of thin films. The main goal of this work was the nanocomposites ZF-LHS synthesis with the SILD method and to study the effect of the anionic composition on the structural features and electrocatalytic properties during HER in alkaline water-alcohol solution.

\section{Experimental technique}

\subsection{Materials}

For the synthesis, glass and silicon plates (substrates) with dimensions of $26 \times 10 \times 1 \mathrm{~mm}$, as well as plates of nickel foil with dimensions of $25 \times 5 \times 0.1 \mathrm{~mm}$ were used. Oxides were removed from the nickel foil via abrasion with sandpaper (P120 grit). Immediately before the synthesis, all the substrates were treated with acetone to remove mechanical and chemical impurities. All the reagents were chemically pure. The water for solutions was distilled with a conductivity of $5 \mathrm{M} \Omega \mathrm{cm}$.

\subsection{Synthesis procedure}

For ZF-LHS synthesis by SILD method were used two solutions. The precursor of solution No. 1 was $\left(\mathrm{NH}_{4}\right)_{2}$ $\mathrm{Fe}\left(\mathrm{SO}_{4}\right)_{2}$ with a concentration of $0.01 \mathrm{~mol} \mathrm{~L}^{-1}$. The solution No. 2 was contained an ammonium complex of $\mathrm{Zn}$ (II) salts, consisting of zinc salt $\left(\mathrm{Zn}\left(\mathrm{NO}_{3}\right)_{2}, \mathrm{ZnSO}_{4}\right.$ or $\left.\mathrm{ZnCl}_{2}\right)(C=0.01 \mathrm{~mol} \mathrm{~L}-1), \mathrm{NH}_{4} \mathrm{NO}_{3}(C=0.15 \mathrm{~mol} \mathrm{~L}-1)$ and a dropwise added solution of $1 \mathrm{M} \mathrm{NH}_{4} \mathrm{OH}$ to $\mathrm{pH}=10$.

During the synthesis, the substrate, fixed in the sample holder, was immersed for 30 seconds in chemical beakers with $\left(\mathrm{NH}_{4}\right)_{2} \mathrm{Fe}\left(\mathrm{SO}_{4}\right)_{2}$, distilled water, mixed $\mathrm{Zn}$ (II) salt, $\mathrm{NH}_{4} \mathrm{NO}_{3}$, and $\mathrm{NH}_{4} \mathrm{OH}$ solution, and again into distilled water. Such processing represented one SILD cycle, which was repeated 30 times (Fig. 1). As a result, nanocomposites with $\mathrm{Zn}\left(\mathrm{NO}_{3}\right)_{2}$ (ZF-LHS-1), $\mathrm{ZnSO}_{4}$ (ZF-LHS-2) and $\mathrm{ZnCl}_{2}$ (ZF-LHS-3) reagents were obtained. Also, for a comparative analysis of the effect of heat treatment, the samples were thermally treated for 1 hour at $250{ }^{\circ} \mathrm{C}$ in the air (ZF-LHS-1T, ZF-LHS-2T, ZF-LHS-3T).

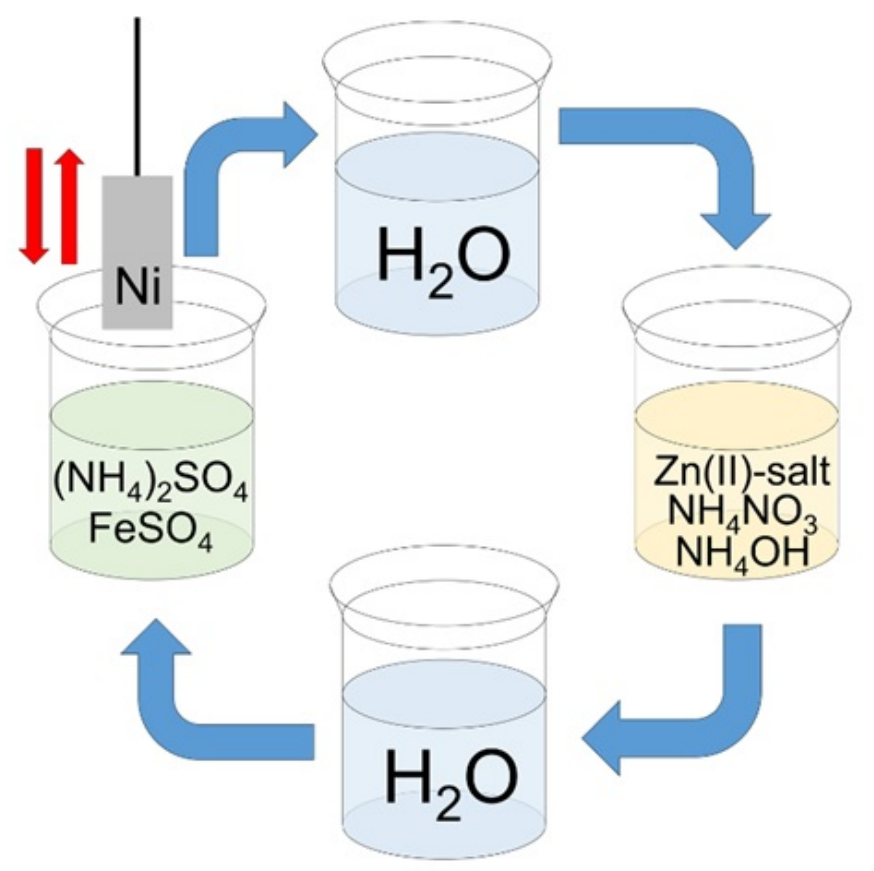

FIG. 1. Scheme of SILD-synthesis of ZF-LHS 


\subsection{Physicochemical characterization}

The elemental composition of the samples and their morphological features were examined by X-ray microanalysis and scanning electron microscopy (SEM) using an FEA Quanta 200 microscope equipped with an EDX attachment. $\mathrm{X}$-ray phase analysis of the samples was carried out by powder X-ray diffraction using a Rigaku SmartLab III multifunctional X-ray diffractometer (Co K $\alpha$ radiation, $\lambda=0.179026 \mathrm{~nm}$ ). The qualitative X-ray phase composition was determined on the basis of comparing the sample pattern with the data of JCPDS and ICSD. The analysis of the main functional groups located on the surface of the synthesized samples was carried out by the FTIR analysis with spectrophotometer Shimadzu IRTracer-100, equipped with the adapter "Specac". Analysis of the results of FTIR spectroscopy was carried out by comparing the position and intensity of the main absorption bands with the data presented in the literature on similar systems.

\subsection{Electrocatalytic performance}

Electrocatalytic studies of materials for HER were carried out on an Elins P-20X potentiostat-galvanostat in a three-electrode cell shown in Fig. 2.

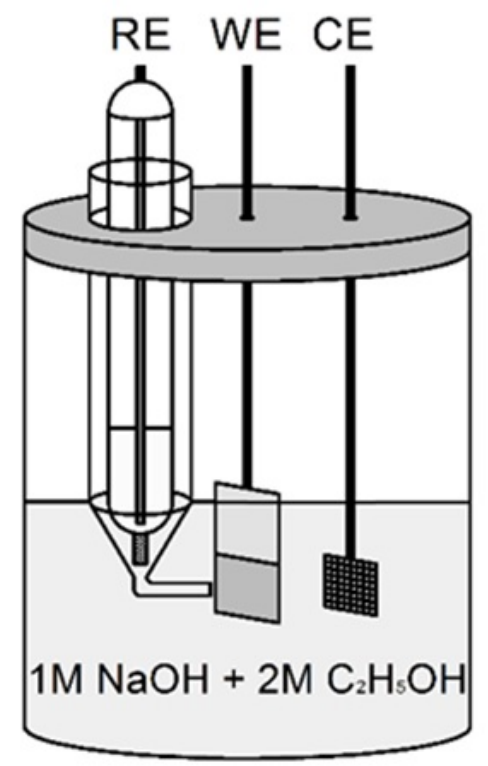

FIG. 2. Three-electrode cell for electrochemical measurements

The working electrode (WE) was a nanocomposite deposited by the SILD method on a nickel substrate with an electroactive surface of $1 \mathrm{~cm}^{2}$. $\mathrm{Ag} / \mathrm{AgCl}$ and platinum electrodes were used respectively as a reference electrode (RE) and counter electrode (CE). Overpotential value was calculated according to the Nernst equation for a reversible hydrogen electrode (RHE): $E_{R H E}=E_{\mathrm{Ag} / \mathrm{AgCl}}^{o}+E_{\mathrm{Ag} / \mathrm{AgCl}}+0.059 \mathrm{pH}$, where $E_{\mathrm{Ag} / \mathrm{AgCl}}^{o}$ is the standard potential of $\mathrm{Ag} / \mathrm{AgCl}$ electrode $(0.202 \mathrm{mV}), E_{\mathrm{Ag} / \mathrm{AgCl}}$ is the potential of the working electrode relative to $\mathrm{Ag} / \mathrm{AgCl}$. All measurements were carried out under standard conditions $\left(T=25^{\circ} \mathrm{C}, P=1 \mathrm{~atm}\right.$.) in an aqueous solution consisting of 2 mole absolute ethanol and 1 mole $\mathrm{NaOH}(\mathrm{pH}=14)$. Cyclic $\mathrm{CV}$ curves were taken in the potential range from open circuit potential to $1.5 \mathrm{~V}$ with a sweep rate of $5 \mathrm{mV} \mathrm{s}^{-1}$. Qualitatively, the working overpotential of the sample was determined from the $\mathrm{CV}$ curves at a current density of $10 \mathrm{~mA} \mathrm{~cm}{ }^{-2}$. Electrochemical measurements were performed without IR-compensation.

\section{Results and discussion}

As a result of carrying out SILD synthesis according to the method described above, three samples were obtained, differing in the anion type, which was used to prepare the reaction solution No. 2 - zinc nitrate (ZF-LHS-1), zinc sulfate (ZF-LHS-2) and zinc chloride (ZF-LHS-3). The chemical composition of the synthesized samples was studied by the EDX method, the results are shown in Fig. 3a. According to these data, all samples contain oxygen, sulfur, zinc, and iron in their composition. The atomic fraction of iron significantly exceeds the zinc content and this difference from the sample ZF-LHS-1 to the sample ZF-LHS-3 is growing. This is due to a change in the ionic strength of the reaction solution No. 2, depending on the zinc salts. Using various zinc salts leads to different cations sorption $\left(\mathrm{Zn}^{2+}\right.$ 
and $\mathrm{Fe}^{2+}$ ) on the surface of the substrate and the forming varied film of the product. A small number of sulfur atoms, registered in all samples, is apparently due to the occurrence of sulfate groups of the reaction solution No. 1.
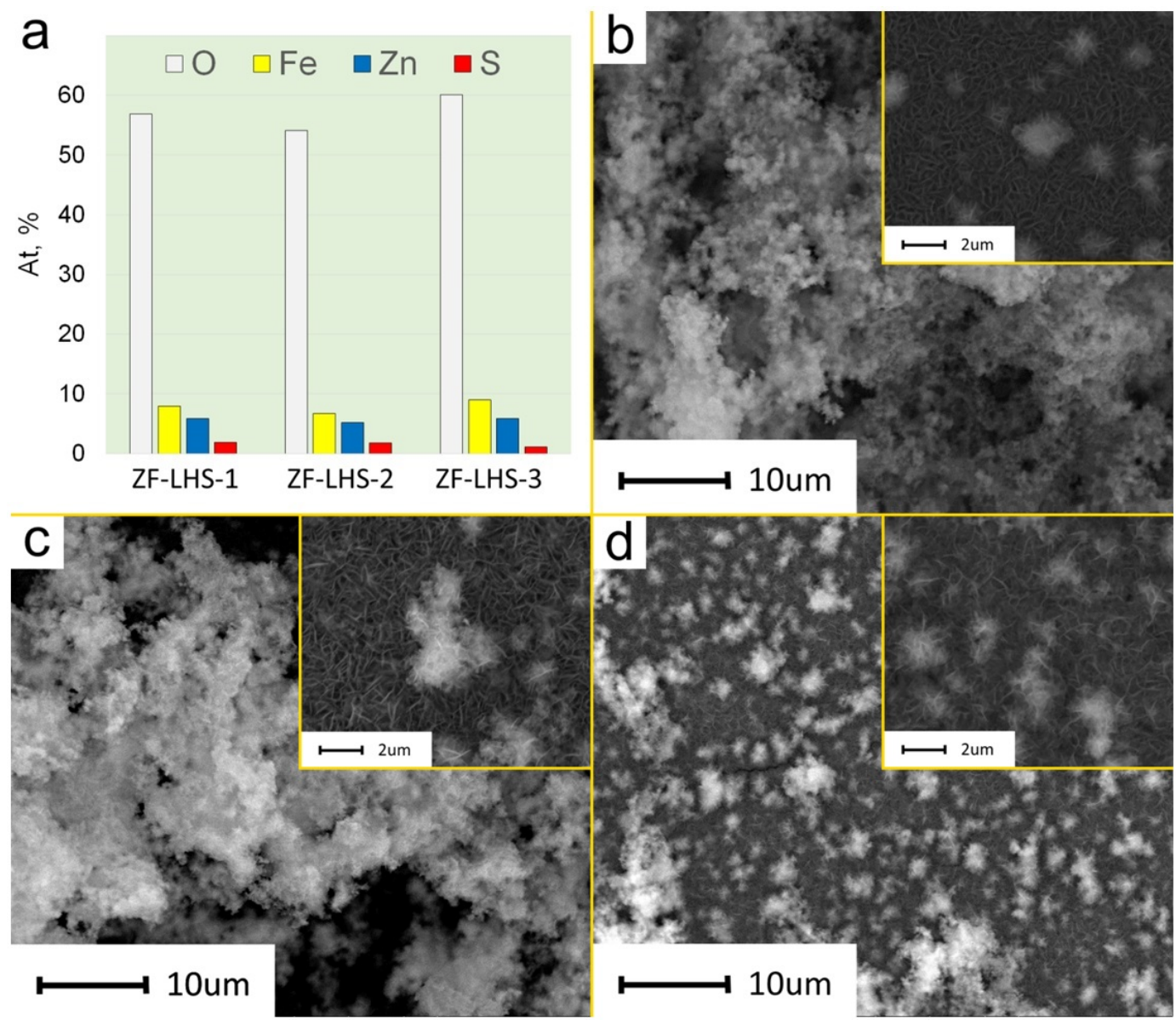

FIG. 3. Results of EDX analysis (a) and SEM micrographs (b-d) of samples ZF-LHS: b - ZF-LHS1, c - ZF-LHS-2, d - ZF-LHS-3

The morphology of the samples obtained by the SILD method is presented in Fig. 3b-d. According to this data, continuous films consisting of small crystals agglomerated into complex structures of various shapes are deposited on the surface of the Si-substrate. The morphology of individual crystals can be attributed to the morphology of $2 \mathrm{D}$ crystals and the effect of the zinc salt anion, apparently, is reduced to the effect on the agglomeration of the forming nanocrystals. The synthesized nanocrystals represent two types of agglomerates - a continuous film on the surface of the Si-substrate and spherical agglomerates on the surface of the continuous film. In some cases, coral-like agglomerates are also observed, which are the result of long-term growth and association of spherical agglomerates. In general, the morphological structure of the obtained compounds is characteristic of the samples are formed by the SILD method [39].

However, differences in the elemental composition, which slightly affect the morphology of nanocrystals, manifest themselves in the results of X-ray diffraction of the samples (Fig. 4). As shown from the data, two phases can be present in the composition of the films: zinc-iron layered hydroxy sulfate $\mathrm{Zn}_{2} \mathrm{Fe}_{4}(\mathrm{OH})_{12} \mathrm{SO}_{4} \cdot 8 \mathrm{H}_{2} \mathrm{O}$ (ICSD card No. 9013993) and iron(III) hydroxide $\mathrm{Fe}(\mathrm{OH})_{3}$ (JCPDS card No. 00-013-0092). The ZF-LHS-1 sample contains only the $\mathrm{Zn}_{2} \mathrm{Fe}_{4}(\mathrm{OH})_{12} \mathrm{SO}_{4} \cdot 8 \mathrm{H}_{2} \mathrm{O}$ phase, and the ZF-LHS-2 and ZF-LHS-3 samples also contain the Fe $(\mathrm{OH})_{3}$ phase, whose reflex intensity increases from the ZF-LHS-2 sample to the ZF-LHS-3. This suggests that the increase in the proportion of $\mathrm{Fe}$ atoms relative to $\mathrm{Zn}$ in the composition of the synthesized samples from ZF-LHS-1 to ZF-LHS-3 leads to the appearance of the second phase of iron (III) hydroxide, which is fixed along with the phase of a zinc-iron layered hydroxy sulfate.

The broadening of the X-ray diffraction lines of the ZF-LHS and iron(III) hydroxide indicates that they are nanostructured, which confirms the results of SEM analyses (Fig. 3c-d). The calculation of the average size of coherent scattering regions for individual reflexes of these phases gives a value from 6 to $17 \mathrm{~nm}$. The uneven broadening of the 


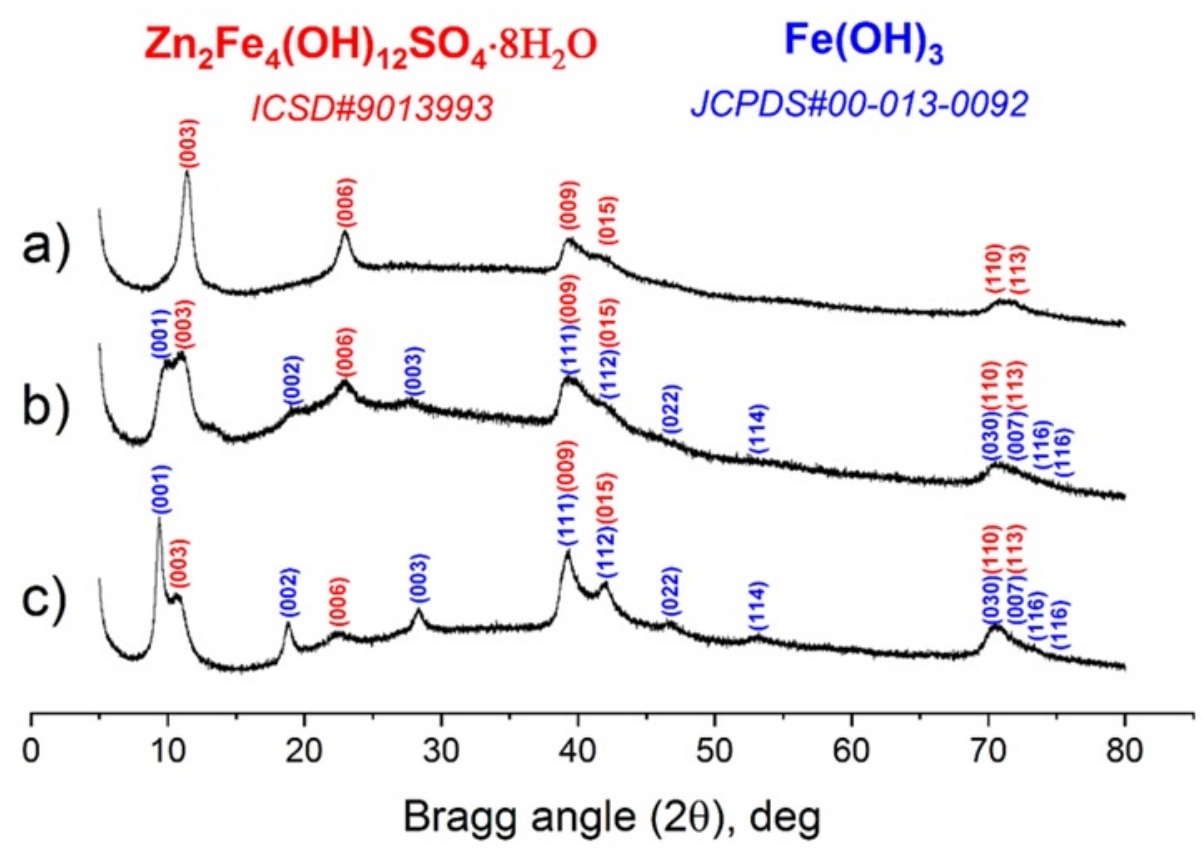

FIG. 4. X-ray diffraction patterns of the samples ZF-LHS: a) ZF-LHS-1, b) ZF-LHS-2, c) ZF-LHS-3

X-ray diffraction lines of the ZF-LHS and iron (III) hydroxides by individual crystallographic directions indicates that the formed crystals have anisotropy of shape and morphology of $2 \mathrm{D}$ nanocrystals.

The analysis of the main functional groups located on the surface of the obtained samples was carried out by FTIR, the results are shown in Fig. 5. The absorption bands of 1640 and $3250 \mathrm{~cm}^{-1}$ relate, respectively, to the deformation and stretching vibrations of the $\mathrm{O}-\mathrm{H}$ bond in water molecules adsorbed on the surface of the samples. Since these absorption bands are high-intensity, they shield the absorption bands from vibrations of O-H bonds in the ZF-LHS and iron(III) hydroxide structural groups. The presented spectra also contain a set of absorption bands at 607,975 , and $1090 \mathrm{~cm}^{-1}$, corresponding to the vibrations of the S-O bonds in the sulfate groups of ZF-LHS. In addition, the intense absorption band at $1360 \mathrm{~cm}^{-1}$ is clearly visible, which corresponds to the vibrations of the $\mathrm{C}-\mathrm{O}$ bond in the carbonate group. It's associated with the sorption of $\mathrm{CO}_{2}$ from the air by the developed surface of the samples [34-40]. The absorption bands of the $\mathrm{Zn}-\mathrm{O}$ and $\mathrm{Fe}-\mathrm{O}$ bonds in the wavenumber region of $300-600 \mathrm{~cm}^{-1}$ cannot be identified because of their diffuse shape [36]. This is due to the imperfect crystal structure of the main phases - ZF-LHS and iron(III) hydroxide, which are formed as a result of synthesis by the SILD method.

Thus, the surface composition of the obtained compounds is almost completely consistent with the volume composition established on the basis of the results of EDX and PXRD studies, with the exception of components $\left(\mathrm{H}_{2} \mathrm{O}\right.$ and $\mathrm{CO}_{2}$ ) that are adsorbed onto the surface of the sample during the synthesis and subsequent storage of the substance.

According to the method presented in the work, coatings were obtained on the surface of nickel electrodes and their electrocatalytic characteristics were studied, the results are shown in Fig. 6. The appearance of the electrodes obtained by deposition of the nanocomposite on the nickel substrate is shown in Fig. 6a. The red color of the precipitate indicates that iron(III) compounds are present in its composition.

Important characteristics in evaluating the effectiveness of electrode material for the hydrogen evolution reaction are the overpotential $(\eta)$ at some fixed value of the current load (for example, $10 \mathrm{~mA} \mathrm{~cm}{ }^{-2}$ ), the slope of Tafel plot $(\log (j)-\eta)$ and the stability material, including its short non-stationary mode.

As can be seen from the graph shown in Fig. 6b, the overpotential on a clean nickel substrate at a current density of $10 \mathrm{~mA} \mathrm{~cm}^{-2}$ is $286 \mathrm{mV}$, which corresponds to the literature data [15]. For ZF-LHS-2 and ZF-LHS-3 nanocomposites, the overpotential value at the same current density is 337 and $365 \mathrm{mV}$ before heat treatment and 278 and $280 \mathrm{mV}$ after (ZF-LHS-2T and ZF-LHS-3T), respectively. Thus, the change in the magnitude of the overpotential for these samples after heat treatment is within the limits of error. However, the ZF-LHS-1 sample after heat treatment (ZF-LHS-1T) shows the best result among the studied samples - the overpotential value at a current density of $10 \mathrm{~mA} \mathrm{~cm}{ }^{-2}$ was $260 \mathrm{mV}$. Based on this, we can conclude that it is necessary to apply heat treatment after the synthesis of the samples.

Fig. $6 \mathrm{c}$ presents the results of the analysis of voltammograms in the Tafel plot for heat-treated samples. The Tafel slope (coefficient $b$ ) in these plot indicates a change in overpotential value with a 10 -fold increase in current density. 


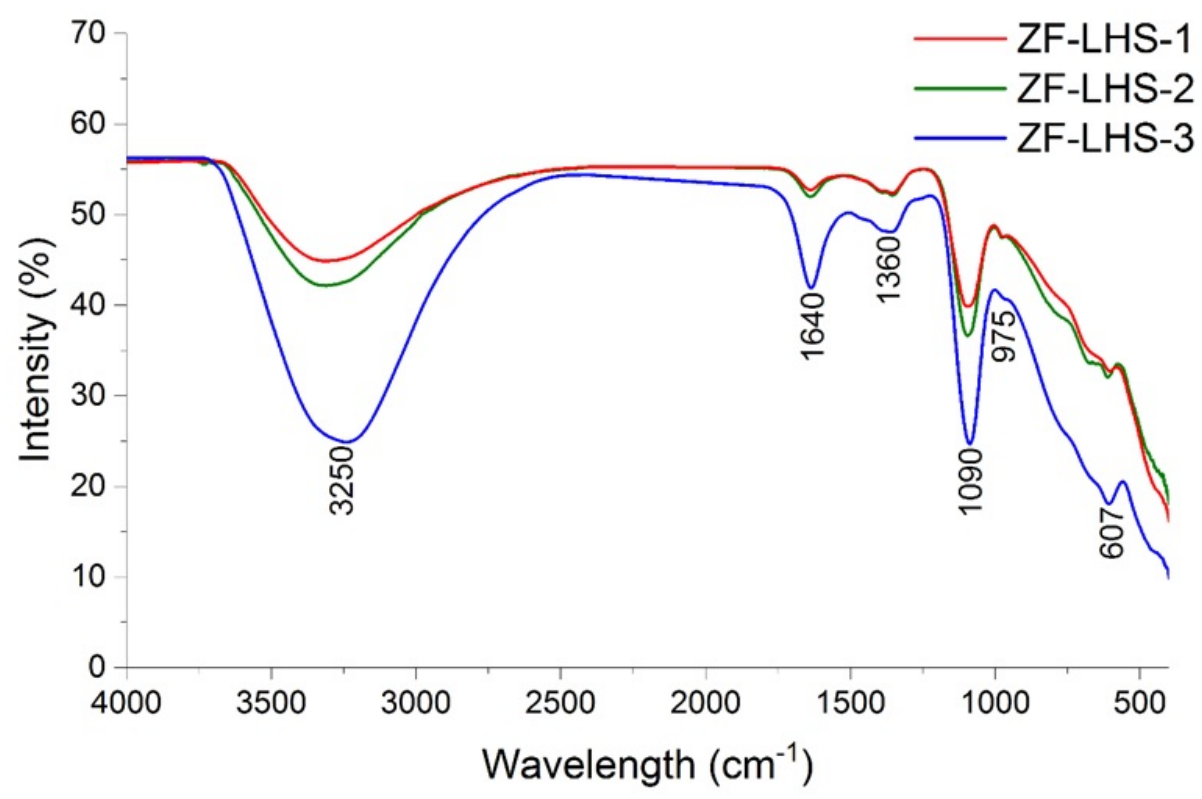

FIG. 5. FTIR spectra of synthesized samples ZF-LHS

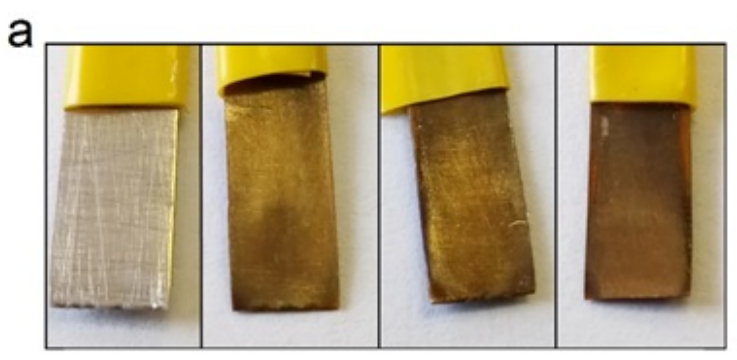

$\mathrm{Ni}$ $\mathrm{Ni}$
substrate

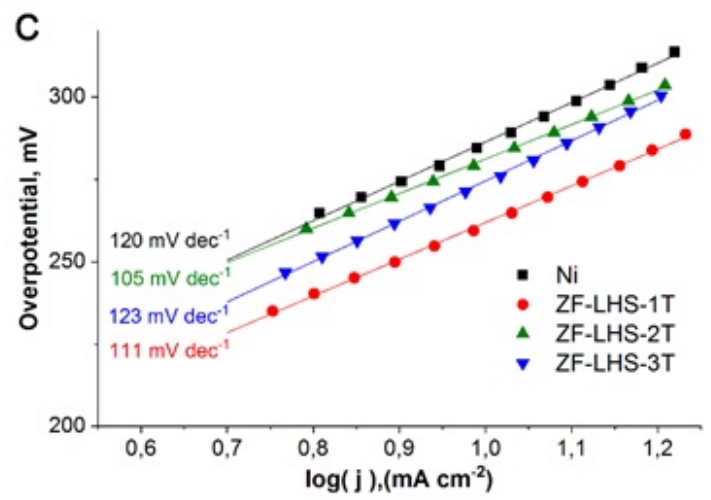

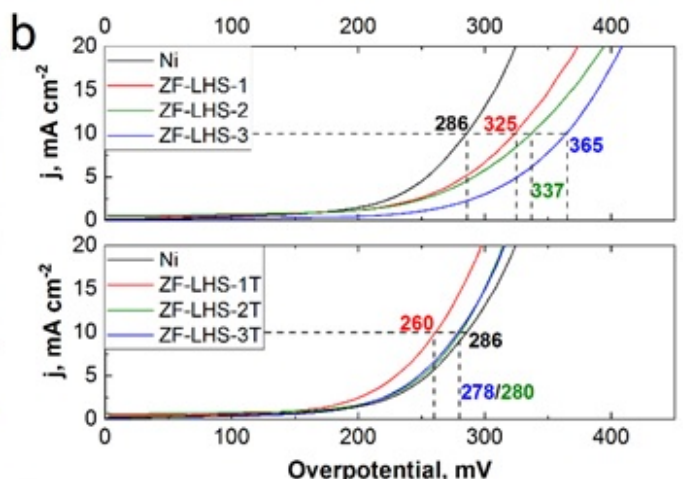

d

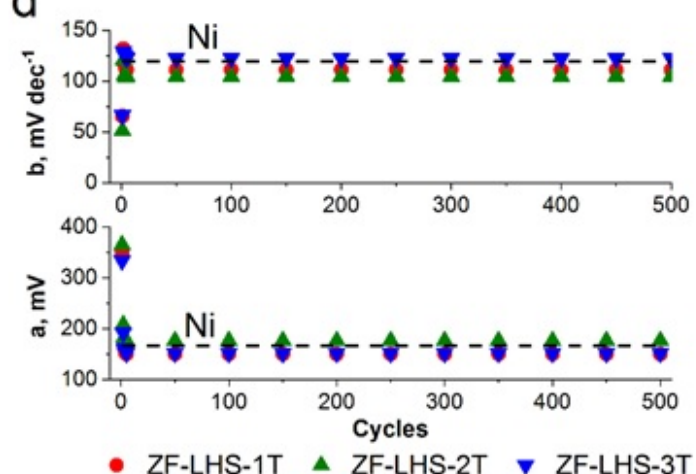

FIG. 6. Electrochemical properties of ZF-LHS: a) Appearance of electrodes; b) CV curves of synthesized nanocomposites; c) Tafel plot of synthesized electrodes; d) Change in the coefficients of the Tafel equation for 500 cycles 
Thus, reducing the Tafel slope for ZF-LHS-1T and ZF-LHS-2T samples (111 mV and $105 \mathrm{mV}$, respectively) relative to pure nickel $(120 \mathrm{mV})$ has an economic advantage in electrochemical reforming, which is $8-12 \%$ in terms of power consumption. For the ZF-LHS-3T sample, the Tafel slope value is $123 \mathrm{mV}$, which is slightly higher than the value for a pure nickel electrode.

The reason for this difference in the electrochemical behavior of electrocatalysts, both between samples and in the presence or absence of heat treatment; this is the result of the structuring degree, which determines the electrical properties of the surface coating. With an increase in the ordering of the structure in the series ZF-LHS-3T - ZF-LHS$2 \mathrm{~T}-\mathrm{ZF}-\mathrm{LHS}-1 \mathrm{~T}$, as can be seen from the microphotographs in Fig. 3b-d, the nanocomposite represents a coral-like structure and its electrochemical characteristics improve: the overpotential of HER is reduced and Tafel slope is decreased. The structuring process is promoted by the proportionality of the anions of zinc salts, to the anions present in solutions No. 1 and No. 2 and participating in the SILD synthesis $-\mathrm{NO}^{3-}$ and $\mathrm{SO}_{4}^{2-}$. In the case of using zinc chloride as a precursor, the structure of the compound (ZF-LHS-3T) is more chaotic and is distributed in a slightly conducting iron oxide (III).

The stability of the work and short non-stationary mode of the electrode materials are presented as a graphical dependence in Fig. 6d. It can be noted that starting from the 5th cycle of operation, the values of the coefficients of the Tafel equation change slightly, and we can speak about the stationary mode. Further cycling of the synthesized electrocatalytic materials up to 500 cycles practically does not change the values of the coefficients $a$ and $b$, which indicates their high cyclic stability.

\section{Conclusion}

This paper proposes a simple and effective technique for producing a nanocomposite coating based on $\mathrm{Zn}_{2}$ $\mathrm{Fe}_{4}(\mathrm{OH})_{12} \mathrm{SO}_{4} \cdot 8 \mathrm{H}_{2} \mathrm{O}$ and $\mathrm{Fe}(\mathrm{OH})_{3}$ on the surface of a nickel electrode by the SILD method. It was shown that by varying the anionic component of the reaction solution $\left(\mathrm{NO}^{3-}, \mathrm{SO}_{4}^{2-}\right.$ or $\left.\mathrm{Cl}^{-}\right)$, it is possible to effectively control the phase composition of the nanocomposite coating from pure zinc-iron layered hydroxy sulfate to its equal molar ratio with $\mathrm{Fe}(\mathrm{OH})_{3}$. It was established that the obtained nanocomposite consists of $2 \mathrm{D} \mathrm{Zn}_{2} \mathrm{Fe}_{4}(\mathrm{OH})_{12} \mathrm{SO} 4 \cdot 8 \mathrm{H}_{2} \mathrm{O}$ and $\mathrm{Fe}(\mathrm{OH})_{3}$ nanocrystals with an average size of 6-17 nm, which cover the nickel electrode and develop its specific surface with the formation of coral-like agglomerates. The synthesized electrode materials were investigated in the process of electrochemical reforming of ethanol in an aqueous medium with the aim of producing hydrogen. It was shown that the developed coatings based on $\mathrm{Zn}_{2} \mathrm{Fe}_{4}(\mathrm{OH})_{12} \mathrm{SO}_{4} \cdot 8 \mathrm{H}_{2} \mathrm{O}$ and $\mathrm{Fe}(\mathrm{OH})_{3}$ lead to a decrease in the overpotential value compared to the pure nickel electrode by $\sim 10 \%$, and these coatings also reduce the power consumption for this process by $8-12 \%$. This effect is most pronounced after the heat treatment of these compositions for 1 hour at $250^{\circ} \mathrm{C}$ in air. Together, with short non-stationary mode and with the high cyclic stability of these materials, the system under investigation can be considered as a promising basis of electrocatalyst for HER processes from ethanol in an alkaline medium.

\section{References}

[1] Glebova N.V., Nechitailov A.A., Krasnova A.O., et al. Cathode of hydrogen fuel cell, with modified structure and hydrophobicity. Russ. J. Appl. Chem., 2015, 88, P. 769-774.

[2] Krasnova A.O., Agafonov D.V., Glebova N.V., et al. Technological Aspects of Hydrogen Fuel Cell Electrodes with Controlled Porosity and Transport Properties. Altern. Energy. Ecol., 2019, 4-6, P. 51-64.

[3] Mitra M.A. Study on Advances in Hydrogen Fuel Cells. Electrical Engineering Open Access Open Journal, 2019,1 , P. 1-4.

[4] Sharaf O.Z., Orhan M.F. An overview of fuel cell technology: Fundamentals and applications. Renew. Sustain. Energy. Rev., 2014, 32, P. 810853.

[5] Akhairi M.A.F., Kamarudin S.K. Catalysts in direct ethanol fuel cell (DEFC): An overview. Int. J. Hydrogen Energy, 2016, 41, P. 4214-4228.

[6] Brandon N.P., Parkes M.A. Fuel Cells: Materials. Ref. Modul. Mater. Sci. Mater., 2016, P. 1-6.

[7] Tuomi S., Santasalo-Aarnio A., Kanninen P., Kallio T. Hydrogen production by methanol-water solution electrolysis with an alkaline membrane cell. J Power Sources, 2013, 229, P. 32-35.

[8] Gutiérrez-Guerra N., Jiménez-Vázquez M., Serrano-Ruiz J.C., et al. Electrochemical reforming vs. catalytic reforming of ethanol: A process energy analysis for hydrogen production. Chem Eng Process: Process Intensif, 2015, 95, P. 9-16.

[9] Hasa B., Vakros J., Katsaounis A.D. Study of low temperature alcohol electro-reforming. Mater Today Proc, 2018, 5, P. $27337-27344$.

[10] Hasa B., Vakros J., Katsaounis A.D. Effect of $\mathrm{TiO}_{2}$ on Pt-Ru-based anodes for methanol electroreforming. Appl Catal. B Environ, 2018, 237, P. 811-816.

[11] Bambagioni V., Bevilacqua M., Bianchini C., et al. Self-sustainable production of hydrogen, chemicals, and energy from renewable alcohols by electrocatalysis. Chem. Sus. Chem., 2010, 3, P. 851-855.

[12] De Lucas-Consuegra A., Calcerrada A.B., De La Osa A.R., Valverde J.L. Electrochemical reforming of ethylene glycol. Influence of the operation parameters, simulation and its optimization. Fuel Process Technol, 2014, 127, P. 13-19.

[13] Caravaca A., Sapountzi F.M., De Lucas-Consuegra A., et al. Electrochemical reforming of ethanol-water solutions for pure H2 production in a PEM electrolysis cell. Int J Hydrogen Energy, 2012, 37, P. 9504-9513. 
[14] Safizadeh F., Ghali E., Houlachi G. Electrocatalysis developments for hydrogen evolution reaction in alkaline solutions - A Review. Int. J. Hydrogen Energy, 2015, 40, P. 256-274.

[15] Nikolic V.M., Maslovara S.L., Tasic G.S., et al. Kinetics of hydrogen evolution reaction in alkaline electrolysis on a Ni cathode in the presence of Ni-Co-Mo based ionic activators. Appl Catal B Environ, 2015, 179, P. 88-94.

[16] Rüetschi P., Delahay P. Hydrogen overvoltage and electrode material. A theoretical analysis. J. Chem. Phys., 1955, 23, P. 195-199.

[17] Kubisztal J., Budniok A., Lasia A. Study of the hydrogen evolution reaction on nickel-based composite coatings containing molybdenum powder. Int. J. Hydrogen Energy, 2007, 32, P. 1211-1218.

[18] Pêrez-Alonso F.J., Adán C., Rojas S., et al. Ni-Co electrodes prepared by electroless-plating deposition. A study of their electrocatalytic activity for the hydrogen and oxygen evolution reactions. Int. J. Hydrogen Energy, 2015, 40, P. 51-61.

[19] Siddeswara D.M.K., Mahesh K.R.V., Sharma S.C., et al. ZnO decorated graphene nanosheets: an advanced material for the electrochemical performance and photocatalytic degradation of organic dyes. Nanosyst.: Physics, Chem., Math., 2016, 7, P. 678-682.

[20] Alekseeva O.A., Naberezhnov A.A., Stukova E.V., Popkov V.I. The effect of barium titanate admixture on the stability of potassium nitrate ferroelectric phase in $(1-\mathrm{x}) \mathrm{KNO}_{3}+(\mathrm{x}) \mathrm{BaTiO}_{3}$ composites. St. Petersbg. Polytech. Univ. J. Phys. Math., 2015, 1, P. $229-234$.

[21] Mylarappa M., Lakshmi V.V., Mahesh K.R.V., et al. Electro chemical and photo catalytic studies of $\mathrm{MnO}_{2}$ nanoparticle from waste dry cell batteries. Nanosyst.: Physics, Chem., Math., 2016, 7, P. 657-661.

[22] Gimaztdinova M.M., Tugova E.A., Tomkovich M.V. Synthesis of $\mathrm{GdFeO}_{3}$ nanocrystals via glycine-nitrate combustion. Condens Phases Interfaces, 2016, 18, P. 422-431.

[23] Kodintsev I., Tolstoy V., Lobinsky A. Room temperature synthesis of composite nanolayer consisting of $\mathrm{AgMnO}_{2}$ delafossite nanosheets and Ag nanoparticles by successive ionic layer deposition and their electrochemical properties. Mater. Lett., 2017, 196, P. 54-56.

[24] Eftekhari A. Electrocatalysts for hydrogen evolution reaction. Int. J. Hydrogen Energy, 2017, 42, P. $11053-11077$.

[25] Wang H., Gao L. Recent developments in electrochemical hydrogen evolution reaction. Curr. Opin Electrochem, 2018,7, P. 7-14.

[26] Zou X., Zhang Y. Noble metal-free hydrogen evolution catalysts for water splitting. Chem. Soc. Rev., 2015, 44, P. 5148-80.

[27] Mahmood N., Yao Y., Zhang J.W., et al. Electrocatalysts for Hydrogen Evolution in Alkaline Electrolytes: Mechanisms, Challenges, and Prospective Solutions. Adv. Sci., 2018, 5, P. 1700464.

[28] Voiry D., Yang J., Chhowalla M. Recent Strategies for Improving the Catalytic Activity of 2D TMD Nanosheets Toward the Hydrogen Evolution Reaction. Adv. Mater., 2016, 28, P. 6197-6206.

[29] Shi Y., Zhang B. Recent advances in transition metal phosphide nanomaterials: Synthesis and applications in hydrogen evolution reaction. Chem. Soc. Rev., 2016, 45, P. 1529-1541.

[30] Ojha K., Saha S., Dagar P., Ganguli A.K. Nanocatalysts for hydrogen evolution reactions. Phys. Chem. Chem. Phys., 2018, 20, P. 6777-6799.

[31] Tolstoy V.P. Successive ionic layer deposition. The use in nanotechnology. Russ. Chem. Rev., 2006, 75, P. 161-175.

[32] Lobinsky A.A., Tolstoy V.P., Kodinzev I.A. Electrocatalytic properties of $\gamma$-NiOOH nanolayers, synthesized by successive ionic layer deposition, during the oxygen evolution reaction upon water splitting in the alkaline medium. Nanosyst.: Physics., Chem., Math., 2018, 9, P. 669-675.

[33] Lobinsky A.A., Tolstoy V.P. Synthesis of 2D Zn-Co LDH nanosheets by a successive ionic layer deposition method as a material for electrodes of high-performance alkaline battery-supercapacitor hybrid devices. RSC Adv, 2018, 8, P. 29607-29612.

[34] Tolstoy V.P., Kuklo L.I., Gulina L.B. Ni(II) doped FeOOH 2D nanocrystals, synthesized by Successive Ionic Layer Deposition, and their electrocatalytic properties during oxygen evolution reaction upon water splitting in the alkaline medium. J. Alloys. Compd., 2019, 786,P. 198204.

[35] Pathan H.M., Lokhande C.D. Deposition of metal chalcogenide thin films by successive ionic layer adsorption and reaction (SILAR) method. Bull. Mater. Sci., 2004, 27, P. 85-111.

[36] Ho S.M. Chemical Science Review and Letters Synthesis of binary metal chalcogenides using SILAR method: Review. Chem. Sci. Rev. Lett., 2015, 4, P. 1305-1310.

[37] Popkov V.I., Tolstoy V.P., Omarov S.O., Nevedomskiy V.N. Enhancement of acidic-basic properties of silica by modification with CeO 2 $\mathrm{Fe}_{2} \mathrm{O}_{3}$ nanoparticles via successive ionic layer deposition. Appl. Surf. Sci., 2019, 473, P. 313-317.

[38] Popkov V.I., Tolstoy V.P., Nevedomskiy V.N. Peroxide route to the synthesis of ultrafine $\mathrm{CeO}_{2}-\mathrm{Fe}_{2} \mathrm{O}_{3}$ nanocomposite via successive ionic layer deposition. Heliyon, 2019, 5, P. e01443.

[39] Kuklo L.I., Tolstoy V.P. Successive ionic layer deposition of $\mathrm{Fe}_{3} \mathrm{O}_{4} @ \mathrm{HxMoO}_{4} \cdot \mathrm{nH}_{2} \mathrm{O}$ composite nanolayers and their superparamagnetic properties. Nanosyst.: Physics., Chem., Math., 2017, 7, P. 1050-1054.

[40] Nakamoto K. Infrared and Raman Spectra of Inorganic and Coordination Compounds. In: Griffiths PR (ed) Handbook of Vibrational Spectroscopy. John Wiley \& Sons, Ltd, Chichester, UK, 2006. 